\title{
Special feature: preliminaries towards ontological reconstruction of economics-theories and simulations
}

\author{
Yuji Aruka ${ }^{1}$
}

Published online: 15 November 2017

(C) Japan Association for Evolutionary Economics 2017

In the era of classical political economy, the method was ontological centric. But, in the last century, the method was replaced with the belief of so-called hypothesis testing, in particular, efficient-market hypothesis testing. The idea of hypothesis testing generally presumes that an object to be tested is really unknown. This is reminiscent of agnosticism. In statistical test, while there is some unknown process $f$ in itself, there are supposed to be alternative statistical models to represent an imprecise but a supposed nearly true process. A best practical way to detect $f$ may be then a comparison of alternative statistical models $\left\{g_{1}, g_{2}\right\}$ by the famous Akaike Information Criterion (AIC), for example. ${ }^{1}$ This kind of statistical customs, however, is categorized within null-hypothesis orientation. ${ }^{2}$ The acceptance or rejection does not mean any visualization of the unknown process under test.

The statistical test of efficiency can simply judge whether there exists "market" whose attribute is more efficient or not. Even if a model with statistically higher efficiency were chosen, the test would never state how such an efficient-market was constructed. The test only states that an unknown market might be efficient. Thus, even if any stochasticity should be incorporated into some general equilibrium model, the stochastic parts would make the system neither realistic nor empirically verified, so that a dynamic stochastic general equilibrium model will not be bestowed reality. An unknown market is not resolved at all. In ontology, on the contrary, "how to exist" matters. An entity specific to a particular domain is

\footnotetext{
1 As the number of estimated parameters in the model $(K)$ is smaller while the maximum value of the likelihood function for the model $(L)$ is greater, AIC $[=2 K-2 \log (K)]$ is then smaller.

2 This is equivalent to compare the information lost from using $g_{1}$ and one lost from using $g_{2}$ to represent $f$. If AIC using $g_{1}$ is smaller than AIC using $g_{2}$, the model $g_{1}$ is judged better fitted.
}

Yuji Aruka

aruka@tamacc.chuo-u.ac.jp

1 Chuo University, Hachioji, Tokyo 192-0393, Japan 
constructed by ontological brocks, which are either virtual or physical existing in the domain.

Ontology in information science, ${ }^{3}$ a fortiori, makes us build some ontological construction, whether virtual or physical, using artificial intelligence. Due to a drastic change of the social system, the efficient-market hypothesis has lost its validity. It seems to us unavoidable to restore ontology to economics. However, this does not mean to return to the approach of classical political economy again. We should learn a new ontology defined in information science. It is noted that "entity" is already embodied as operator/function in Wolfram's Mathematica. Entity can be of functional form in information science.

As artificial intelligence is employed to run entities, it is easier to argue their classes, instances, attributes, their relationships, and functional terms among complex interactions which are mathematically not identified in advance. Thus, an ontological reasoning on the market domain easily brought an idea to apply agentbased modelling (ABM) to emulate an actual entity such as actual market, macro economy, and so on. Among them, a market simulator such as U-Mart system ${ }^{4}$ can emulate an actual exchange market, potentially in some cases become a miniature of an actual market itself. That is to say, the artificial market is an ontological experiment in the market domain to reproduce a market. To employ ABM, without restricting excessively a domain under research and/or damaging functional terms structured by existing entities, we will be able to reproduce some complicated interactions.

To part with the efficiency hypothesis in the domain of production, some ontological consideration may be required. A custom sanctified by long practice in production was to presuppose optimizers and their environments fitted to them. As Hildenbrand (1981) noticed, the traditional production function is described as the projection of $Y$ on the input space for some $X$ of the input space is $V$ :

Maximize $X$ for $(V, X)$ in $Y$.

As an optimizing rule/agent is imposed in advance, the domain of technology set is then limited to a convex set of original single activities.

Hildenbrand (1981, 1097) mentioned:

[T] he economic relevance of the efficient production function is questionable. Other concepts of production functions for an industry are indeed conceivable; one might take into account certain institutional barriers to factor mobility in aggregating the individual production sets.

Leaving the special space restricted by the traditional production function, we can observe various possible combinations to accept institutional effects. Broadening the space, from where technology can be chosen, implies to introduce all possible combinations of activities. By nature, on the other hand, a zonotope of production permits to represent all possible combinations of activities. It then turns out that traditional economics is entirely irrelevant to an ontological thinking about

\footnotetext{
3 See Wikipedia's article of Ontology (information science): https://en.wikipedia.org/wiki/Ontology_ (information_science).

4 As for the details of the U-Mart system, see Kita et al. (2016).
} 
how the production function exists. Given four basic activities, a zonotope of production is described in Fig. 1.

The same consideration as a zonotope of production applies to gene analysis, as Wright (1932) described a diversity of huge size, which allelomorphs of genes can generate, as Fig. 2. Figures 1 and 2 are of formally similar forms. Furthermore, we can immediately grasp a common idea between both figures. We notice that both are based on the same ontological reasoning. Incidentally, Fig. 1 in the above corresponds to Fig. 3 of Aruka's article (2017) of this special issue.

Interestingly, Alan Turing exhibited a model of the Chemical Basis of Morphogenesis in Turing (1952). Here, he suggested that concentrations and asymmetries are keys to understanding evolution starting from the embryo. Evolving dynamics is modeled as a single activator-a single inhibitor model to generate various singularities. There exists an asymmetry between the inhibitor and the activator. The inhibitor's diffusion from one cell to another is much bigger than the activator's one. More interestingly, Turing in 1952 properly predicted that artificial intelligence would reproduce this theory. In 2006, Stefanie Sick et al. by computer simulation on the growth of hair has shown that two types of molecules

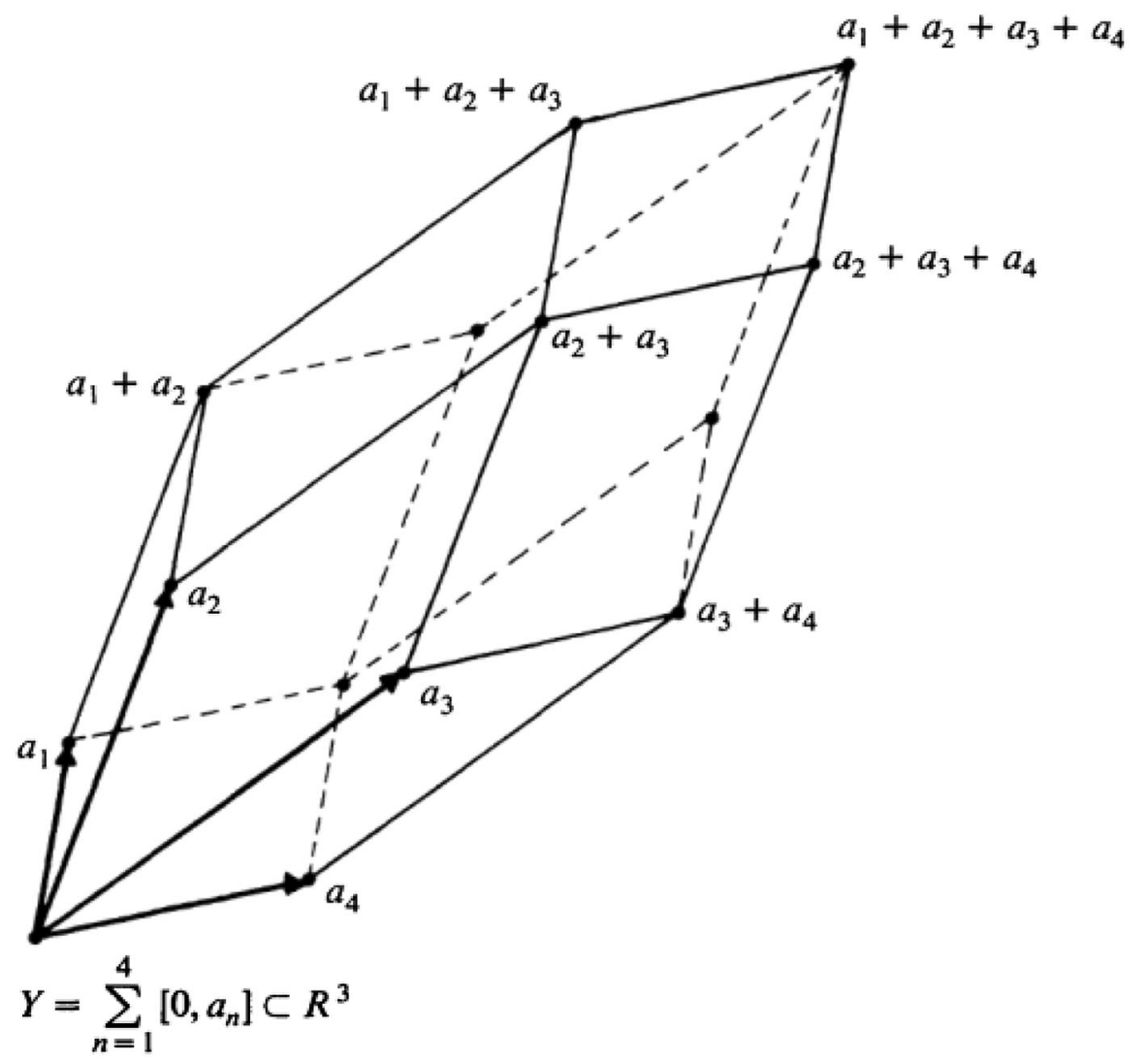

Fig. 1 An alternative production function of four basic activities. Cited from Hildenbrand (1981, 1097) 


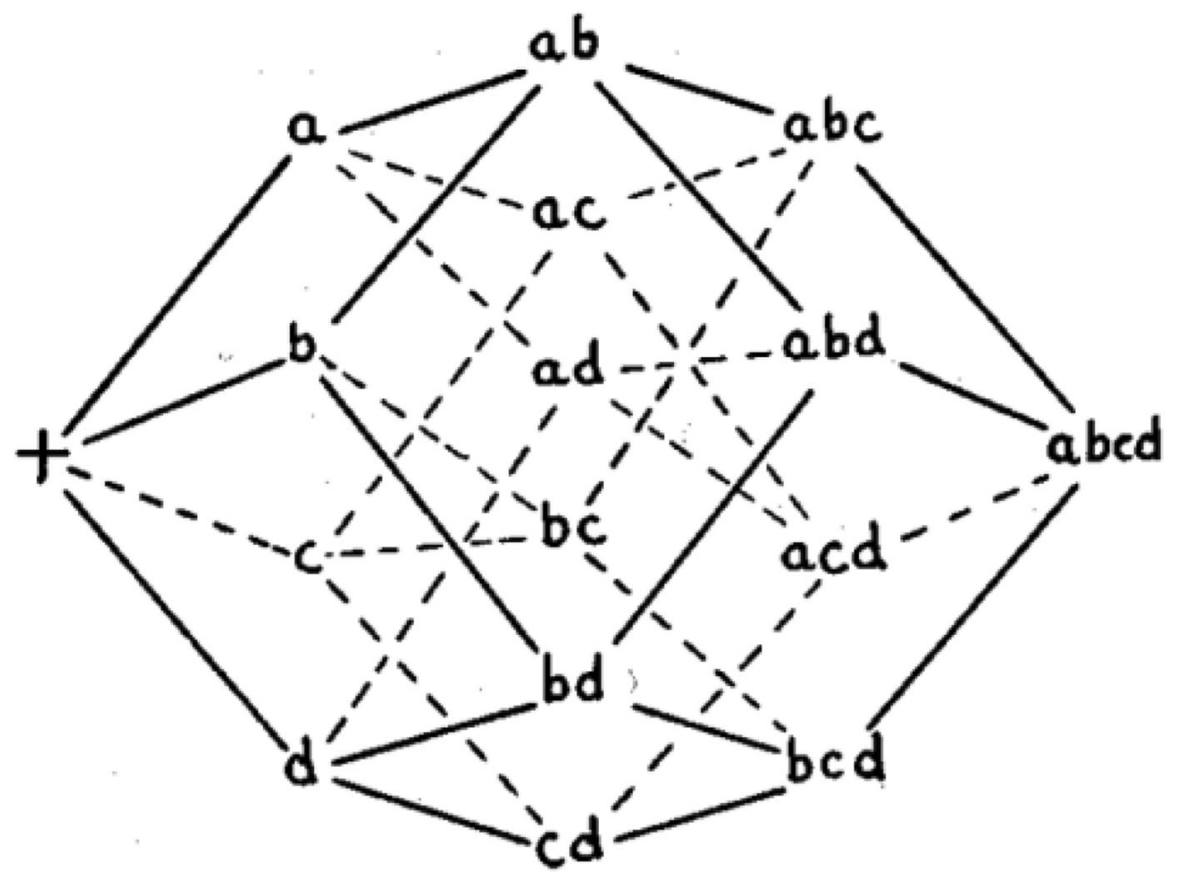

Fig. 2 The 16 homozygous combinations: a; b; c; d are allemorphs. Cited from Wright $(1932,357)$

that play an important role in the growth of hair have all the characteristics of Turing's morphogens. ${ }^{5}$ Moreover, Stephen Wolfram, recently in his blog referred to "The Practical Business of Ontology: A Tale from the Front Lines". ${ }^{6}$ Here, he mentioned the Philosophy of Chemicals. To employ artificial intelligence, in particular, cellular automaton, a practically ontological reasoning will be achieved by resorting to ABM thinking.

The article of Rosser and Rosser (2016) of this special issue shares with the spirit common to Wright and Turing. ${ }^{7}$ By resorting to Thorstein Veblen, this article examined the basis for increasing returns, multiple equilibria, and bifurcations in the evolution of institutions. In our compilation of this special issue, we have first arranged the ontological arguments of economic theory in the two articles of Aruka (2017), and Rosser and Rosser (2016).

For the latter part of this special issue, we then prepared the articles for ABM simulation on Japanese economy and the financial asset market, respectively. In the social system, the means available to us to solve a number of unknowns are often limited. In other words, the number of equations processed in a given system is much smaller than the number of variables. This then causes to raise the discretion

\footnotetext{
5 See Damerow (2015). Here the author exposited Turing (1952) in details.

${ }^{6}$ See Stephen Wolfram's blog: http://blog.stephenwolfram.com/2017/07/the-practical-business-ofontology-a-tale-from-the-front-lines/.

7 See Rosser and Rosser (2017) in Chapter 4 in Aruka and Kirman (2017).
} 
to choose the decision rule. This may be also interpreted as a source of diversity. Characterizing a system depends on what kinds of unknowns are deployed. This criterion was also important in economics to establish general equilibrium since Leon Walras. Focusing on this criterion, Michio Morishima (1984) extensively examined the different characterization of doctrines between Marx and Keynes. The multipliers working in a system varies as a system specification is altered. In this point of view, it is also seen that the well-known hypotheses of either the representative agent or the efficient-market were a method to reduce unknowns boldly.

The article of Ogibayashi and Takashima (2017) adopted Keynesian specification of the system in the context of Morishima, and employed the economic linkage table (Table 5 of Ogibayashi and Takashima). This provides the macro economy to the interaction matrix associated with the balance sheet of agent. For different purposes in accordance with the research target, the interaction matrix will naturally be of wide varieties. The famous EURACE ${ }^{8}$ employed another linkage table different from Ogibayashi's table. In his article, inefficiency in public expenditure, (the ratio of firm subsidies to the sum of firm subsidies and market purchases) and tax policy are studied by comparing the ABM simulation and the actual statistical figures. This article suggests a new idea to measure inefficiencies by ABM.

In the above, we have already referred to the use of artificial market as a useful ontological method. The article of Yagi et al. (2017) employed an artificial market to examine the effects on price formation in financial markets, when the rule for investment diversification was imposed. Here, the artificial market to deal with two assets was designed to experiment in the environment where investors are obliged to follow the rule for investment diversification. This article also exhibited usefulness of an ABM of the financial market.

In March 2016, JAFEE arranged an international conference titled: International Conference on Socio-economic Systems with ICT and Networks. ${ }^{9}$ To focus on the main theme of this conference, as another publication around this conference, we have already compiled a collection titled: Economic Foundations for Social Complexity Science: Theory, Sentiments, and Empirical Laws (Aruka and Kirman 2017). In parallel with this monograph achievement, this special issue has aimed at examining more directly some methodological/ontological issue to reconstruct economics.

\section{References}

Aruka Y (2017) Some new perspectives on the inter-country analysis of the world production system. Evol Inst Econ Rev. https://doi.org/10.1007/s40844-017-0085-2

\footnotetext{
${ }^{8}$ EURACE was a massively parallel agent-based model of the European economy. See Deissenberga et al. (2008).

9 JAFEE 20th Annual Meeting held at UTokyo, March 26/27, 2016. http://c-faculty.chuo-u.ac.jp/ $\sim$ jafee20/.
} 
Aruka Y, Kirman A (eds) (2017) Economic foundations for social complexity science: theory, sentiments, and empirical laws. Springer, Singapore

Damerow J (2015) “The chemical basis of morphogenesis" (1952), by Alan M. Turing. In: The embryo project encyclopedia, Arizona State University

Deissenberga C, der Hoog S, Dawid H (2008) EURACE: a massively parallel agent-based model of the European economy. Appl Math Comput 204(2):541-552

Hildenbrand W (1981) Short-run production functions based on microdata. Econometrica 49(5):1095-1125

Kita H, Taniguchi K, Nakajima Y (eds) (2016) Realistic simulation of financial markets-analyzing market behaviors by the third mode of science. Springer, Tokyo

Morishima M (1984) The economics of industrial society. Cambridge University Press, Cambridge

Ogibayashi S, Takashima K (2017) Influential factors responsible for the effect of tax reduction on GDP. Evol Inst Econ Rev. https://doi.org/10.1007/s40844-017-0080-7

Rosser JB Jr, Rosser MV (2016) Complexity and institutional evolution. Evol Inst Econ Rev. https://doi. org/10.1007/s40844-016-0060-3

Rosser JB, Rosser MV (2017) The evolution of behavioural institutional complexity. In: Aruka Y, Kirman A (eds) Economic foundations for social complexity science: theory, sentiments, and empirical laws. Springer, Singapore, pp 67-88

Turing A (1952) The chemical basis of morphogenesis. Philos Trans R Soc Lond B 237:37-72

Wright S (1932) The roles of mutation, inbreeding, crossbreeding, and selection in evolution. In: Proceeding of international congress of genetics. Ithaca, USA (VI) 1: 356-366

Yagi I, Nozaki A, Mizuta T (2017) Investigation of the rule for investment diversification at the time of a market crash using an artificial market simulation. Evol Inst Econ Rev. https://doi.org/10.1007/ s40844-017-0070-9 